Article

\title{
Sulphated Zirconia as an Eco-Friendly Catalyst in Acylal Preparation under Solvent-Free Conditions, Acylal Deprotection Assisted by Microwaves, and the Synthesis of Anhydro-Dimers of $o$-Hydroxybenzaldehydes
}

\section{Laura Nadxieli Palacios-Grijalva ${ }^{1}$, Deysi Y. Cruz-González ${ }^{1}$, Leticia Lomas-Romero ${ }^{2}$,} Eduardo González-Zamora ${ }^{2}$, Gerardo Ulibarri ${ }^{3}$ and Guillermo E. Negrón-Silva ${ }^{1, *}$

1 Departamento de Ciencias Básicas, UAM-A, Av. San Pablo, No. 180. C.P. 02200, México, D.F., Mexico; E-Mails: lnpg@correo.azc.uam.mx (L.N.P.-G.); dycg@correo.azc.uam.mx (D.Y.C.-G.)

2 Departamento de Química, UAM-I, San Rafael Atlixco, No. 186. C.P. 09340, México, D.F., Mexico; E-Mails: 1lr@xanum.uam.mx (L.L.-R.); egz@xanum.uam.mx (E.G.-Z.)

3 Department of Chemistry \& Biochemistry, Laurentian University, Sudbury, ON P3E2C6, Canada; E-Mail: gulibarri@laurentian.ca

* Author to whom correspondence should be addressed; E-Mail: gns@correo.azc.uam.mx.

Received: 25 August 2009; in revised form: 21 September 2009 / Accepted: 27 September 2009 / Published: 12 October 2009

\begin{abstract}
A solvent-free approach is described for the regioselective synthesis of acylals (1,1-diacetates) in shorter reaction times and higher yields, compared to conventional methodology using solvents. In the protection reaction of the $o$-hydroxybenzaldehyde the formation of acetyl compounds and anhydro-dimers was observed. The deprotection reaction involves microwave (MW) exposure of diluted reactants in the presence of solid sulphated zirconia (SZ) catalyst that can be easily recovered and reused. The sulphated zirconia was recycled several times without any loss of activity.
\end{abstract}

Keywords: sulphated zirconia; solvent-free; microwaves; regioselective; diacetates

\section{Introduction}

Organic transformations are frequently assisted by heterogeneous catalysts which usually provide rate enhancements, yield and/or selectivity improvements, and easier work ups, but the most important 
general advantage of these methods is their contribution to eco-friendly, "green", sustainable chemistry, which involves the design of chemical processes with a view to reducing or even eliminating the use and production of hazardous materials. Recent efforts have focused on limiting the use of organic solvents and their replacement with new, less polluting and cost-effective ecologicallyfriendly processes, a topic of considerable interest to the chemical industry [1-3].

Functional group protection and deprotection strategies are essential to target-oriented synthesis in organic chemistry [4,5]. Aldehydes can be protected as acylals (1,1-diacetates), which are stable compounds in basic and neutral media and easily re-converted into parent aldehydes [6]. In general, 1,1-diacetates are prepared from aldehydes by treatment with acetic anhydride using homogeneous catalysts [7-17]. The methods mentioned above are not entirely satisfactory, owing to the problems of corrosion, tedious work-up, environmental pollution and non recoverable catalysts. Such environmental problems have attracted considerable attention towards the development of alternative processes using novel heterogeneous catalysts [18-29]. In this context, heterogeneous catalysts play a dramatic role with their easy work-up, separation of the catalyst by filtration, high purity of the products, and the possibility of catalyst recycling. The application of sulphated zirconia as a versatile catalyst in organic transformations was enhanced by the comprehensive review published by Reddy et al. [30], and other research groups in subsequent papers [31-33]. Following our work on the application of sulphated zirconia as an eco-friendly catalyst [34-38], we proposed its application in protection reactions under solvent free conditions, the deprotection of the protected moieties assisted by microwaves and the synthesis of anhydro-dimers of $o$-hydroxy-benzaldehydes.

Figure 1. Diffraction pattern of sulphated zirconia.

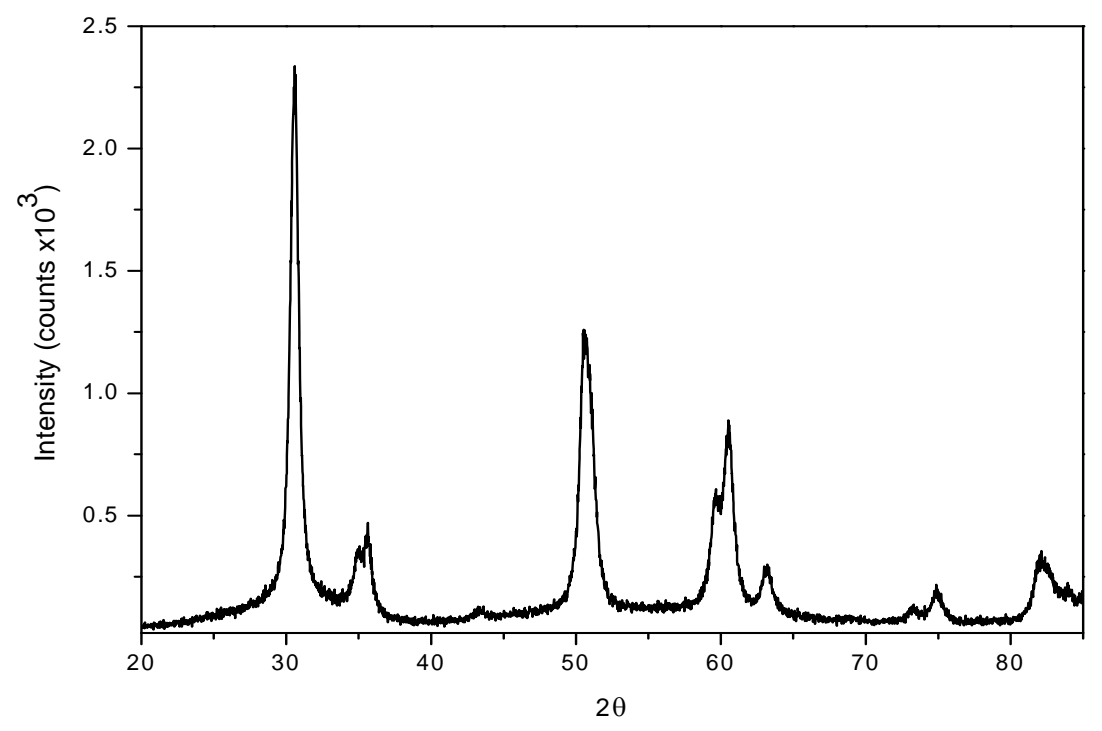

\section{Results and Discussion}

The $X$ ray powder diffraction (XRD) patterns in the $20-65^{\circ} 2 \theta$ range for sulphated zirconia catalysts showed that after calcination the tetragonal phase is the major form present (ICSD collection code: 066787 ), as given by reflections in $2 \theta=30.18^{\circ}$ (with 100 as relative intensity) and the peaks 
located at $34.616^{\circ}, 35.283^{\circ}, 43.002^{\circ}, 50.214^{\circ}, 50.770^{\circ}, 59.291^{\circ}, 60.187^{\circ}, 62.724^{\circ}, 72.894^{\circ}, 74.617^{\circ}$ and $81.768^{\circ}[35]$ (Figure 1).

The study of the nitrogen physisorption provides information regarding the textural properties of the catalysts (Figure 2). The adsorption/desorption isotherm relative to calcinated sample belongs to type IV IUPAC classification, with a type H2-H3 hysteresis loop [39]. It is an isotherm with a steep increment of the adsorbed volume at low pressure and a second one at around $\mathrm{P} / \mathrm{Po}=0.35$, corresponding to pore filling and the existence of mesopores [40]. The textural properties of sulphated zirconia are shown in Table 1 . The surface area $\left(\mathrm{S}_{\mathrm{BET}}\right)$ was calculated by the BET method, the cumulative pore volume $(\mathrm{Vp})$ and the average pore diameter $(\mathrm{Dp})$, were obtained by the $\mathrm{BJH}$ data analysis [41].

Figure 2. Nitrogen adsorption-desorption plot of sulphated zirconia.

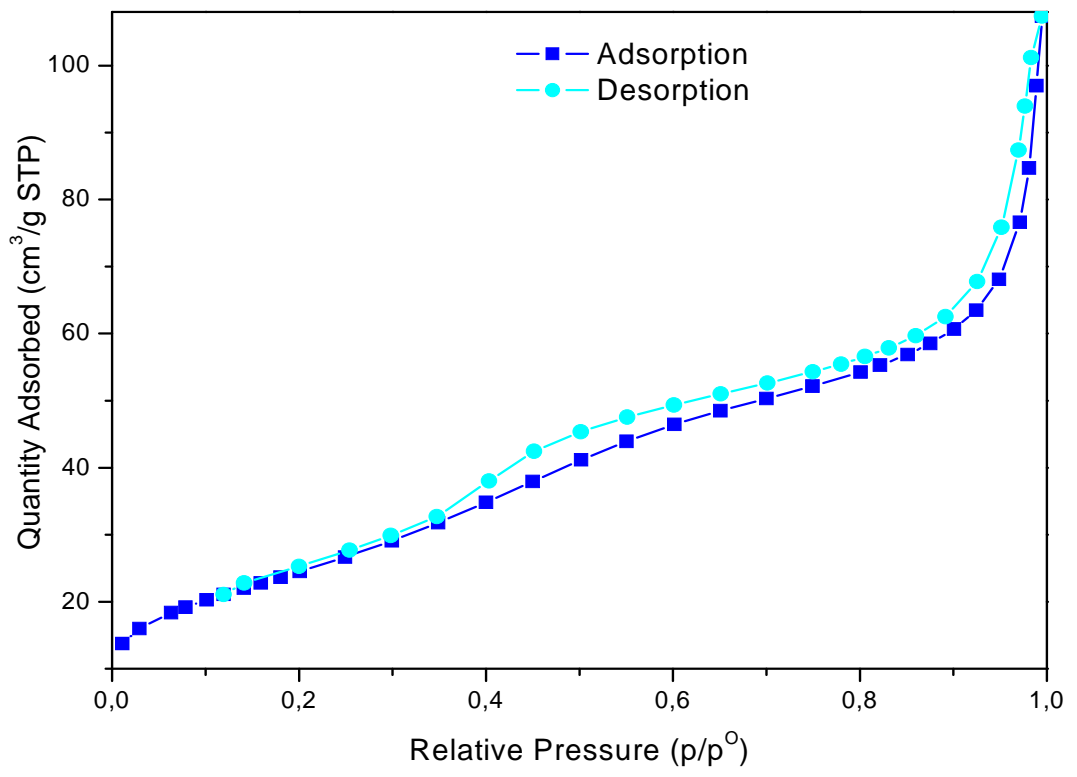

Table 1. Sulphated zirconia surface features.

\begin{tabular}{|c|c|}
\hline Surface area $\left(\mathbf{S}_{\mathbf{B E T}}\right)$ & $90 \mathrm{~m}^{2} / \mathrm{g}$ \\
Pore volume (Vp) & $0.12 \mathrm{~cm}^{3} / \mathrm{g}$ \\
Pore diameter (Dp) & $52.7 \AA$ \\
\hline
\end{tabular}

For testing recyclability, the sulphated zirconia catalyst was filtered after the benzaldehyde protection-deprotection reaction and activated at $500{ }^{\circ} \mathrm{C}$ for $1 \mathrm{hr}$ in air flow; the reactivated sulphated zirconia samples were analyzed by XRD. We observed the presence and increase of the monoclinic phase from the second to the fourth recalcination cycles $\left(2 \theta=28.16^{\circ}\right.$ and $2 \theta=31.44^{\circ}$ reflexions $)$, due to the effect of the reactivation process (Figure 3 ). In a previous work we demonstrated a similar behavior in the synthesis of $\beta$-amino alcohols. [37-38] 
Figure 3. XRD Patterns of reactivated sulphated zirconia.

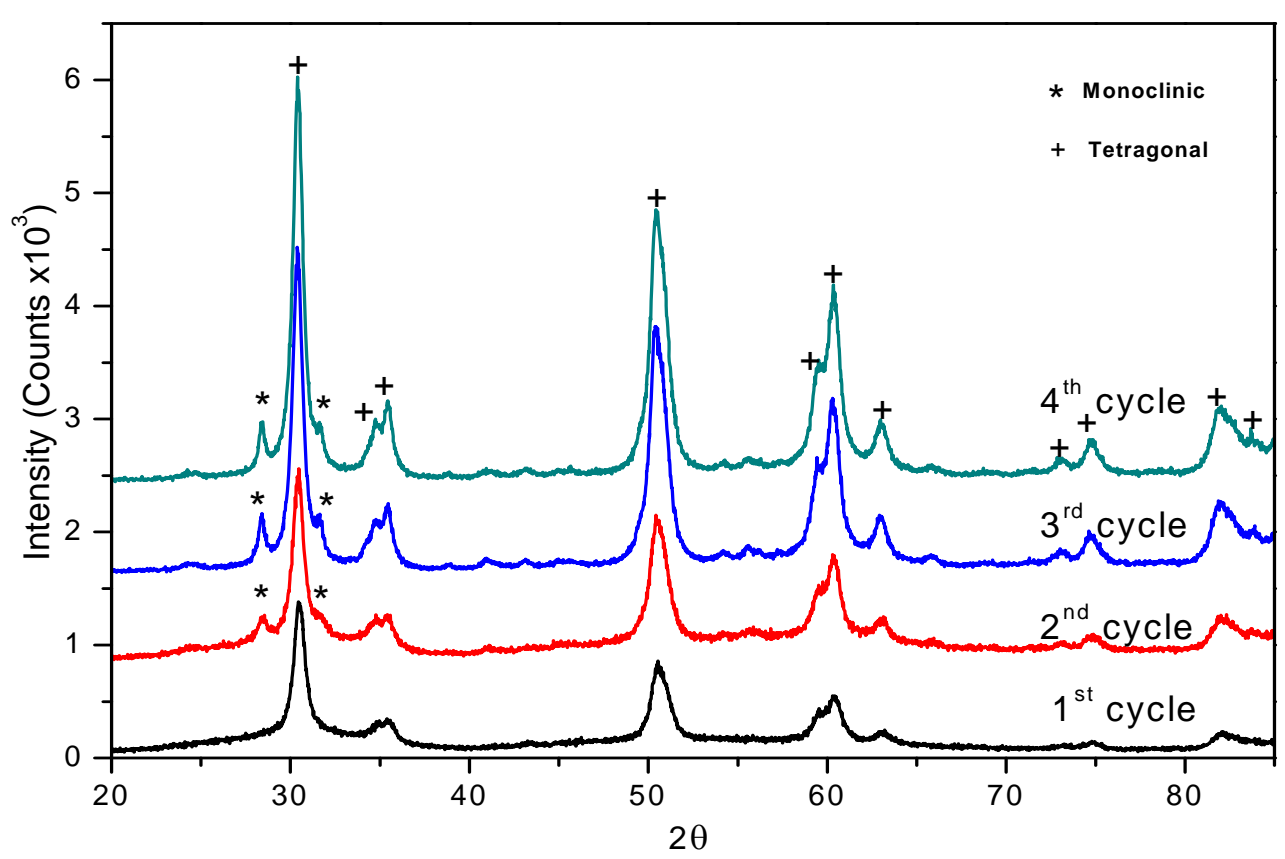

The basic scheme of the acylal protection and deprotection reactions of using sulphated zirconia as acid catalyst is shown in Scheme 1.

Scheme 1. Reaction of protection and deprotection of acylals.<smiles>[R]C([1H])=O</smiles>

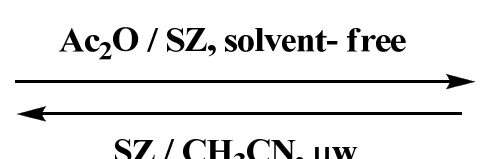<smiles></smiles>

$$
\mathrm{R}=\text { aryl, alkyl }
$$

Table 2 shows isolated yields using some different aldehydes in the solvent free protection reaction at $0{ }^{\circ} \mathrm{C}$, in the presence of sulphated zirconia catalyst.

Table 2. Aldehydes protection under solvent-free conditions.

Entry


Table 2. Cont.

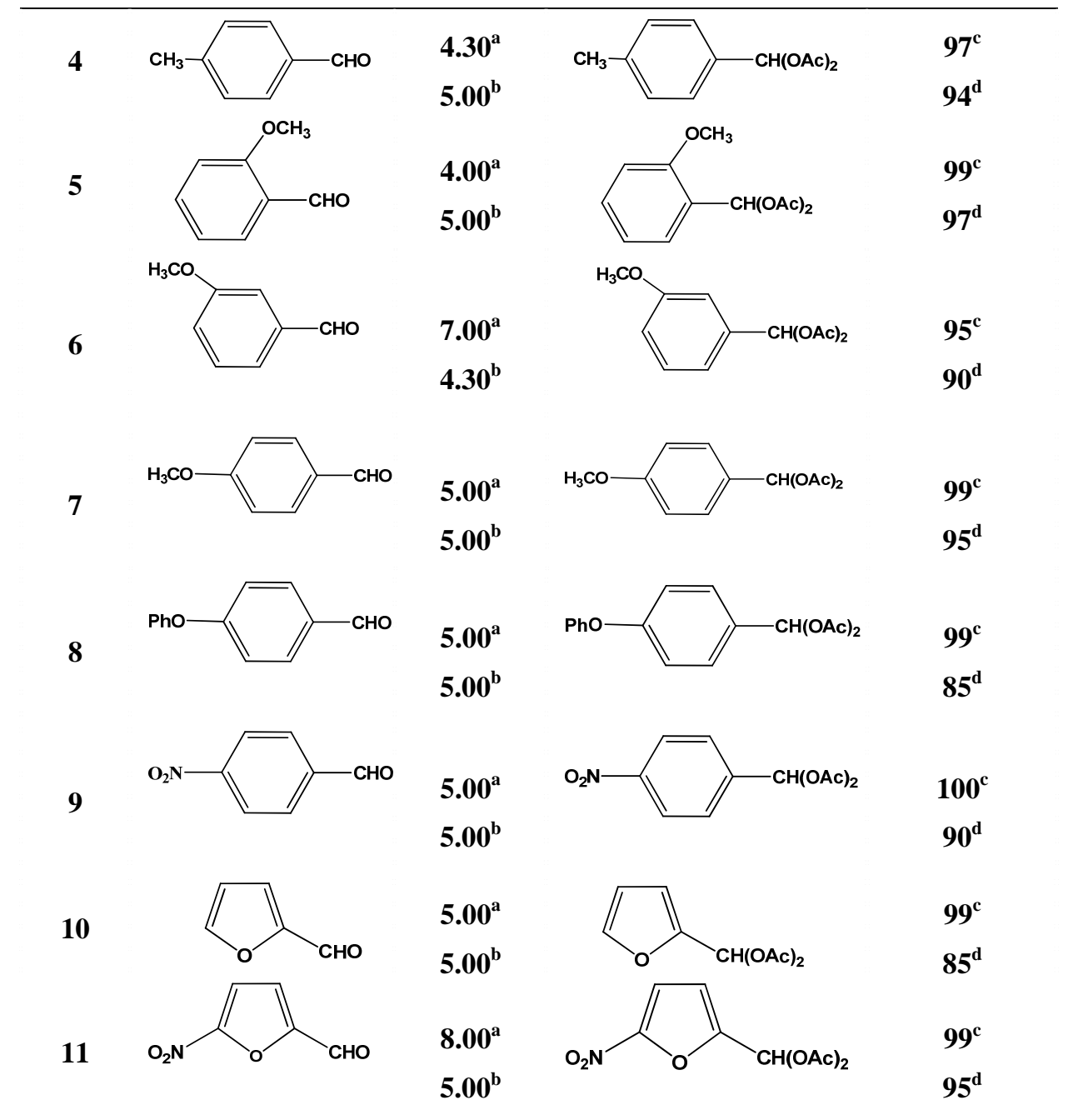

${ }^{\mathrm{a}}$ Reaction conditions: aldehyde $(0.83 \mathrm{mmol})$, acetic anhydride $(2.5 \mathrm{mmol}), \mathrm{SZ}(25 \mathrm{mg})$ and no solvent at $0{ }^{\circ} \mathrm{C} ;{ }^{b}$ Reaction conditions of the published data [35]. ${ }^{\mathrm{c}}$ Yields of solvent free reactions. The products were characterized by IR, ${ }^{1} \mathrm{H}-\mathrm{NMR}$ and Mass Spectroscopy; ${ }^{\mathrm{d}}$ Yields refer to the published data [35].

Table 3 shows the yield of the 1,1-diacetate deprotections to the corresponding aldehydes using catalytic amounts of sulphated zirconia in $\mathrm{CH}_{3} \mathrm{CN}$ at $60{ }^{\circ} \mathrm{C}$ in a microwave reactor.

Table 3. 1,1-Diacetates deprotection reaction to aldehydes.

Entry


Table 3. Cont.

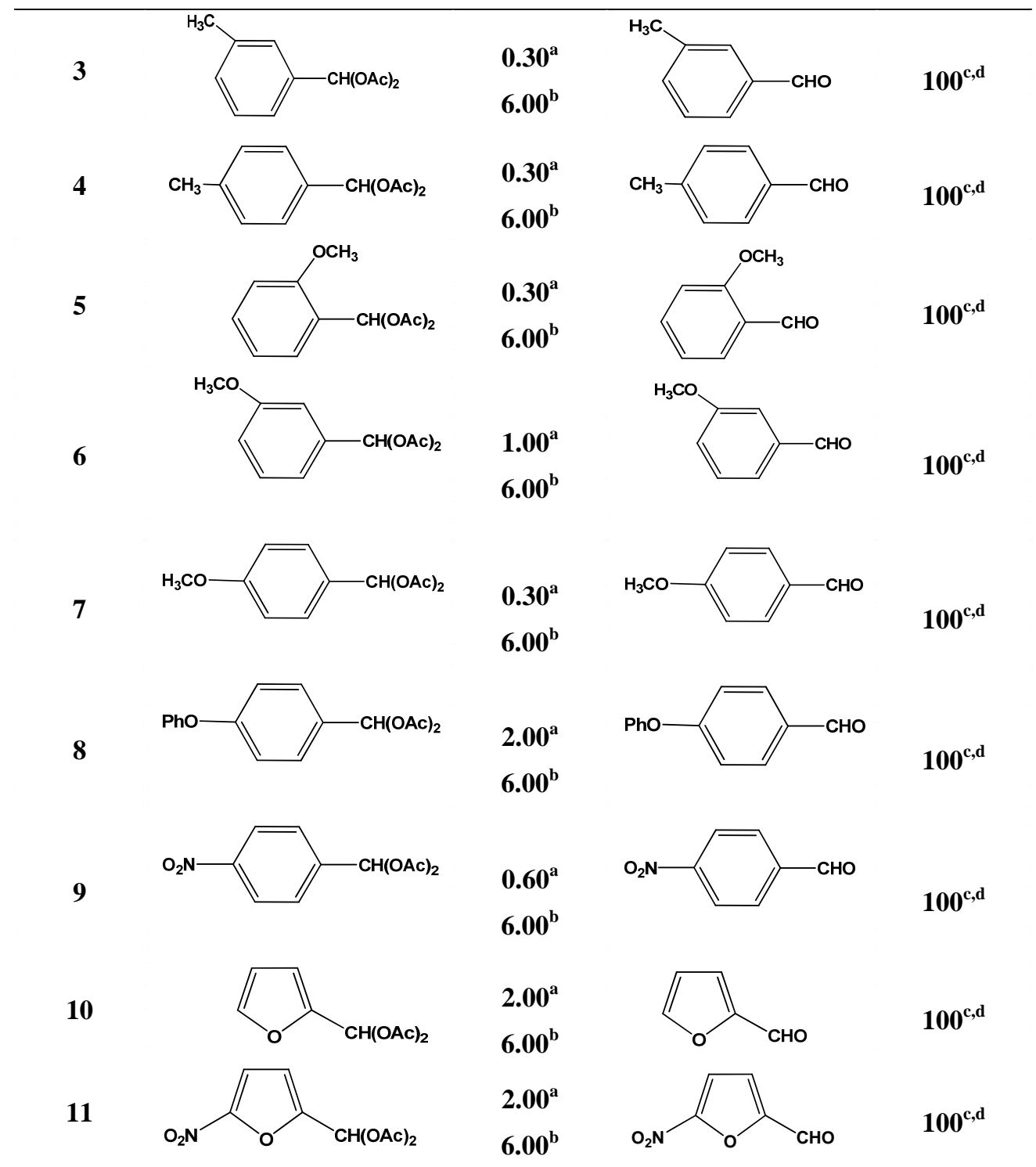

${ }^{\text {a }}$ Reaction conditions: A solution of 1,1-diacetates $(1 \mathrm{mmol})$ in HPLC acetonitrile $(0.5 \mathrm{~mL})$ and $\mathrm{SZ}(25 \mathrm{mg})$ were irradiated at $60{ }^{\circ} \mathrm{C}$ (initial power of $100 \mathrm{~W}$ ) for $10 \mathrm{~min}$ in a self tuning mode CEM lab mate ${ }^{\circledR}$ microwave synthesizer; ${ }^{\mathrm{b}}$ Reaction conditions of the published data [35]; ${ }^{\mathrm{c}}$ Yields of microwave reactions; ${ }^{\mathrm{d}}$ Yields refer to the published data [35].

When the recycled catalysts were tested in the benzaldehyde protection-deprotection reaction, no significant yield changes were observed (Table 4).

Table 4. Aldehyde protection-deprotection reactions in the presence of reactivated sulphated zirconia.

\begin{tabular}{|c|c|c|}
\hline Cycle No. & $\begin{array}{c}\text { \% Yield } \\
\text { Protection }\end{array}$ & $\begin{array}{c}\text { \% Yield } \\
\text { Deprotection }\end{array}$ \\
\hline $1^{\text {st }}$ & 92 & 90 \\
$2^{\text {nd }}$ & 90 & 89 \\
$3^{\text {rd }}$ & 90 & 89 \\
$4^{\text {th }}$ & 86 & 87 \\
\hline
\end{tabular}


We have recently applied the experimental conditions described above to $o$-hydroxybenzaldehyde (1). We observed a $12 \%$ production of the triacetate 2 , and $88 \%$ of the anhydro dimer of o-hydroxybenzaldehyde (6,12-epoxy-6H,12H-dibenzo[b,f][1,5]dioxocin, 3) (Scheme 2).

The classic method of dimerization employs acetic anhydride as the dehydrating agent and solvent using a catalytic amount of sulfuric acid [42], this method provides a $65 \%$ of the dimer 3 . Clearly, the advantages with our experimental conditions are the reusability of the catalyst, the easy separation of pure products and carrying out the reaction in conditions of green chemistry.

Scheme 2. Acylation and autocondensation reaction of $\mathbf{1}$ under classic conditions and by microwaves.

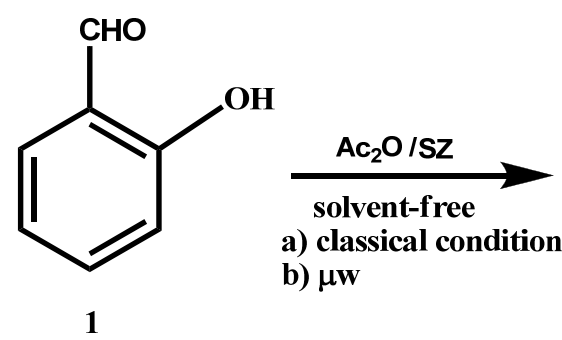

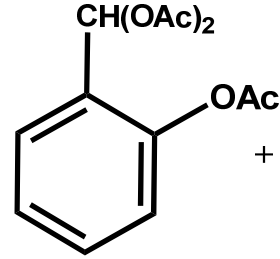

2

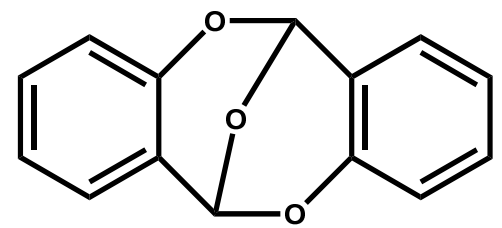

3

If the reaction is assisted by microwave radiation at $0{ }^{\circ} \mathrm{C}$, the formation of the dimer of $o$-hydroxybenzaldehyde, 3, increases to $93 \%$ and the formation of the triacetate, 2 decreases to $7 \%$ (Scheme 2).

In our last work, we demonstrated that some aliphatic and aromatic ketones do not form acylals under the described conditions [35]. From this evidence we studied the dimerization reaction of $o$ hydroxybenzaldehyde and $o$-hydroxyacetophenone.

The dimer 3 of $o$-hydroxybenzaldehyde has been previously described as the result of an aggressive procedure involving $\mathrm{H}_{2} \mathrm{SO}_{4}$, and the dimer 5 (6-methyl-6,12-epoxy-6H,12H-dibenzo[b,f][1,5]dioxocin), is formed in two steps: aggressive dimerization reaction with THF (tetrahydrofuran) at $-78^{\circ} \mathrm{C}$, $n$-butyllithium ( $n$-BuLi ) and $\mathrm{H}_{2} \mathrm{SO}_{4}$, followed by a methylation with methyl iodide [43]. Based on the last the last evidence, our aim was the dimerization reaction between $o$-hydroxybenzaldehyde, 1, and $o$-hydroxyacetophenone, 4 employing sulphated zirconia as catalyst; we observed the formation of $5 \%$ of the corresponding triacetate 2, 17\%yield of the dimer 3 of o-hydroxybenzaldehyde and an $18 \%$ yield of dimer 5 (Scheme 3 ).

Scheme 3. Acylation and condensation reaction of the mixture composed of $\mathbf{1}$ and $\mathbf{4}$ under classical conditions and by microwaves.

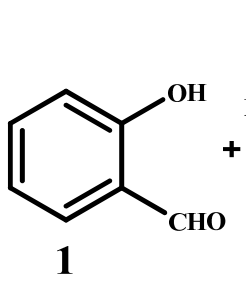<smiles>NC(=O)c1ccccc1O</smiles>

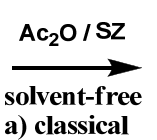

a) classical

b) $\mu \mathbf{w}$<smiles>COc1ccccc1C=[N+]([O-])[O-]</smiles>

2

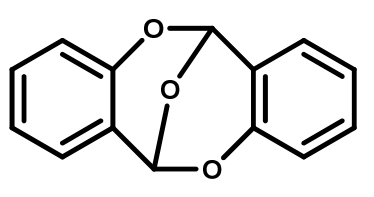

3

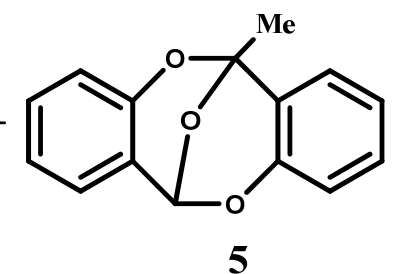

5

Further, when we applied microwave radiation at $0{ }^{\circ} \mathrm{C}$ (initial power $100 \mathrm{~W}$ ), $5 \%$ of product 2 is obtained, 12\% of product 3 and $18 \%$ of product 5 (Scheme 3 ). 
The importance of these anhydro dimers is that they have four of the six rings present in some natural products, and for this reason, Taylor and co-workers have used them as starting materials in the formation of the preussomerins [43].

Furthermore, if $m$-benzaldehyde (6) is used as substrate, the formation of the $\beta$-hydroxyaldehyde dimerization product is not observed and rather the triacetate $\mathbf{7}$ is obtained quantitatively (Scheme 4).

Scheme 4. Acylation and acetylation reactions of $m$-hydroxybenzaldehyde.

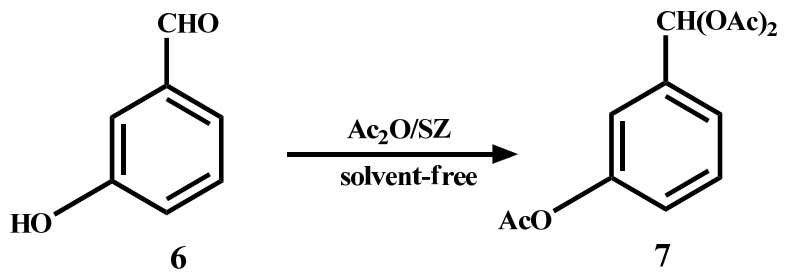

In the case of $p$-hydroxybenzaldehyde (8), it does not form the dimer but, also the triacetal $\mathbf{9}$ and diacetal 10 are formed in 62\% and 18\% yield, respectively (Scheme 5).

Scheme 5. Acylation and acetylation reactions of $p$-hydroxybenzaldehyde.<smiles>O=Cc1ccc(O)cc1</smiles>

8

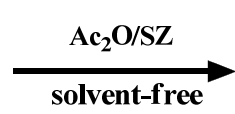<smiles>CC(=O)Oc1ccc(C=O)cc1</smiles>

9<smiles>CC(=O)c1ccc(O)cc1</smiles>

10

\section{Experimental}

\section{General}

Powder X ray diffraction (XRD) was performed with a Philips X'Pert Instrument using Cu K-alpha radiation $(45 \mathrm{kV}, 40 \mathrm{~mA})$. Nitrogen adsorption/desorption isotherms were obtained at $-196{ }^{\circ} \mathrm{C}$ on Micrometrics ASAP 2020 equipment. The reaction products were analyzed by GC-FID (Agilent Technologies $6890 \mathrm{~N})$ equipped with a HP-5 column with the program $70-180{ }^{\circ} \mathrm{C}\left(20^{\circ} \mathrm{C} / \mathrm{min}\right)$ for 6.50 min then $180-280{ }^{\circ} \mathrm{C}\left(15^{\circ} \mathrm{C} / \mathrm{min}\right)$ for $7 \mathrm{~min}$, injector $250{ }^{\circ} \mathrm{C}$, detector $280{ }^{\circ} \mathrm{C}$; the detector was set in the Chemical Ionization mode using methane as reactive gas. Mass spectra were obtained by GC-MS (Agilent Technologies $6890 \mathrm{~N}$, Detector 5973) using methane chemical ionization. ${ }^{1} \mathrm{H}-\mathrm{NMR}$ and ${ }^{13} \mathrm{C}$ NMR spectra was measured at $500 \mathrm{MHz}$ and $125 \mathrm{MHz}$, respectively, on a Bruker Avance DMX-500 spectrometer using $\mathrm{CDCl}_{3}$ as solvent and tetramethylsilane as internal standard. Infrared (IR) spectra were recorded on a Bruker Vector 33 ATR spectrometer. All aldehydes, reagents and solvents were provided by Aldrich and all products were identified by IR, ${ }^{1} \mathrm{H}-\mathrm{NMR},{ }^{13} \mathrm{C}-\mathrm{NMR}$, mass spectra and by comparison of their corresponding melting points. 


\section{Sulphated zirconia synthesis}

Zirconium $n$-propoxide (20 mL, 70\% n-propanol) was mixed with 2-propanol (30 $\mathrm{mL})$ and stirred with a magnetic bar. Then, an acid solution ( $1 \mathrm{~mL} \mathrm{98 \%} \mathrm{sulfuric} \mathrm{acid} \mathrm{in} 3.2 \mathrm{~mL}$ of distilled water) was added dropwise in order to cause the hydrolysis and gelation of the zirconium $n$-propoxide. The solid was filtered and dried at $80{ }^{\circ} \mathrm{C}$ until complete alcohol evaporation, then calcinated in air at $600{ }^{\circ} \mathrm{C}$ for $6 \mathrm{~h}$.

Procedure for the conversion of aldehydes to geminal diacetates under solvent free conditions

A mixture of aldehyde $(0.83 \mathrm{mmol})$, acetic anhydride $(2.50 \mathrm{mmol})$, and sulphated zirconia $(25 \mathrm{mg})$ were placed in a screw-cap vial at $0{ }^{\circ} \mathrm{C}$. The suspension was stirred for the appropriate time (see Table 1). After completion of the reaction, the catalyst was recovered by filtration and the filtrate was extracted with EtOAc $(3 \times 10 \mathrm{~mL})$ and water $(2 \times 10 \mathrm{~mL})$. The organic extracts were combined and washed with $10 \% \mathrm{NaHCO}_{3}$ and dried over anhydrous $\mathrm{Na}_{2} \mathrm{SO}_{4}$. The solvent was evaporated under reduced pressure and the residue was purified on silica gel using light petroleum-ether as eluent to give the pure product 1,1-diacetates. All products were identified via GC-FID mass spectra and analyzed GC-MS, ${ }^{1} \mathrm{H}-\mathrm{NMR},{ }^{13} \mathrm{C}-\mathrm{NMR}$.

Procedure for the deprotection of 1,1 diacetates to aldehydes using Microwave synthesizer

A solution of 1,1-diacetate $(1 \mathrm{mmol})$ in HPLC-grade acetonitrile $(0.5 \mathrm{~mL})$ and sulphated zirconia $(25 \mathrm{mg})$ was introduced into a pressurized reaction tube $(10 \mathrm{~mL})$ equipped with a magnetic stirrer and the mixture was irradiated at $60{ }^{\circ} \mathrm{C}$ (initial power of $100 \mathrm{~W}$ ) for $10 \mathrm{~min}$ in a self tuning mode CEM Labmate ${ }^{\circledR}$ microwave synthesizer. After the reaction, the catalyst was recovered by filtration and the filtrate was extracted with EtOAc and washed with water. The organic extracts were combined and washed with $10 \% \mathrm{NaHCO}_{3}$ and dried over anhydrous $\mathrm{Na}_{2} \mathrm{SO}_{4}$. Then was filtered and evaporated under reduced pressure to give the corresponding aldehyde.

Procedure for the formation of o-hydroxybenzaldehyde dimer (6,12-epoxydibenzo-6H,12Hdibenzo[b,f][1,5] dioxocin, 3) using the conventional thermal method

A mixture of o-hydroxybenzaldehyde $(0.1738 \mathrm{~mL}, 1.66 \mathrm{mmol})$, acetic anhydride $(0.1181 \mathrm{~mL}$, $1.25 \mathrm{mmol})$ and sulphated zirconia $(50 \mathrm{mg})$ were stirred for $3 \mathrm{~h}$. under solvent free conditions. After completion of the reaction, the catalyst was recovered by filtration and the filtrate was extracted with EtOAc $(3 \times 10 \mathrm{~mL})$ and washed with water $(2 \times 10 \mathrm{~mL})$. The organic extracts were combined and washed with $10 \% \mathrm{NaHCO}_{3}$ and dried over anhydrous $\mathrm{Na}_{2} \mathrm{SO}_{4}$. The solvent was evaporated under reduced pressure and the residue was chromatographied on silica gel (light petroleum-ether as eluent) to give the corresponding dimer 3 as a white solid in $80 \%$ yield; m.p. $127-130{ }^{\circ} \mathrm{C}$ (lit. [44] m.p. $130{ }^{\circ} \mathrm{C}$ ); GC-MSD for $\mathrm{C}_{14} \mathrm{H}_{10} \mathrm{O}_{3}$ (m.w.: 226g/mol): $[\mathrm{M}+1]^{+}=227,[\mathrm{M}+29]^{+}=255,[\mathrm{M}+41]^{+}=267$; IR $\left(\mathrm{cm}^{-1}\right): 1590,1455,1069,1611,1217 .{ }^{1} \mathrm{H}-\mathrm{NMR}: \delta(\mathrm{ppm}) 7.28\left(\mathrm{dd}, 2 \mathrm{H}, J_{1}=1.6, J_{2}=7.7 \mathrm{~Hz}\right), 7.21-$ $7.26(\mathrm{~m}, 2 \mathrm{H}), 6.95\left(\mathrm{ddd}, 2 \mathrm{H}, J_{1}=1.1, J_{2}=7.5, J_{3}=8.6 \mathrm{~Hz}\right), 6.87(\mathrm{~d}, 2 \mathrm{H}, J=8.2 \mathrm{~Hz}), 6.35(\mathrm{~s}, 2 \mathrm{H})$;

${ }^{13} \mathrm{C}-\mathrm{NMR}: \delta$ (ppm) 150.50, 130.94, 127.47, 121.51, 119.98, 116.59, 90.13. (lit. [45] ${ }^{13} \mathrm{C}-\mathrm{NMR}$ (125 $\left.\mathrm{MHz}, \mathrm{CDCl}_{3}\right): \delta$ (ppm) 150.55, 130.89, 127.42, 121.46, 120.00, 116.58, 90.14). 
Procedure for the formation of o-hydroxybenzaldehyde dimer (6,12-epoxydibenzo- $6 \mathrm{H}, 12 \mathrm{H}$ dibenzo[b,f][1,5] dioxocin, 3) using microwave irradiation

A mixture of $o$-hydroxybenzaldehyde $(0.1738 \mathrm{~mL}, 1.66 \mathrm{mmol})$, acetic anhydride $(0.1181 \mathrm{~mL}$, $1.25 \mathrm{mmol})$ and sulphated zirconia $(50 \mathrm{mg})$ were introduced into a pressurized tube $(10 \mathrm{~mL})$ equipped with a magnetic stirrer, which was irradiated in solvent free conditions to $0{ }^{\circ} \mathrm{C}$ (initial power of $100 \mathrm{~W}$ ) for $30 \mathrm{~min}$. After reaction, the catalyst was recovered by filtration and the filtrate was treated as described in the conventional thermal method described above for dimer 3.

Procedure for the preparation of the dimer 6-methyl-6,12-epoxy-6H,12H-dibenzo[b,f][1,5]dioxocin (5) using the conventional thermal method

A mixture of o-hydroxybenzaldehyde $(0.0869 \mathrm{~mL}, 0.83 \mathrm{mmol})$, o-hydroxyacetophenone $(0.2260 \mathrm{~mL}, 1.66 \mathrm{mmol})$, acetic anhydride $(0.11801 \mathrm{~mL}, 1.25 \mathrm{mmol})$ and sulphated zirconia $(50 \mathrm{mg})$ was magnetically stirred in solvent-free conditions at $0{ }^{\circ} \mathrm{C}$ for $6 \mathrm{~h}$. After completion of the reaction, the catalyst was recovered by filtration and the filtrate was extracted with EtOAc $(3 \times 10 \mathrm{~mL})$ and washed with water $(2 \times 10 \mathrm{~mL})$. The organic layer was washed with $10 \% \mathrm{NaHCO}_{3}$ and dried over anhydrous $\mathrm{Na}_{2} \mathrm{SO}_{4}$. The solvent was evaporated under reduced pressure and the residue was purified by silica gel chromatography using $100 \%$ light petroleum-ether as eluent to give the corresponding dimer 5 in $15 \%$ as a white solid with a m.p. $80-83{ }^{\circ} \mathrm{C}$, GC-MSD for $\mathrm{C}_{15} \mathrm{H}_{12} \mathrm{O}_{3}$ (m.w.: $240 \mathrm{~g} / \mathrm{mol}$ ): $[\mathrm{M}+1]^{+}=241$, $[\mathrm{M}+29]^{+}=269,[\mathrm{M}+41]^{+}=281 ; \mathrm{IR}\left(\mathrm{cm}^{-1}\right): 1383,1590,1455,1069,1611,1217 ;{ }^{1} \mathrm{H}-\mathrm{NMR}: \delta(\mathrm{ppm})$ $7.33\left(\mathrm{ddd}, 1 \mathrm{H}, J_{1}=0.4, J_{2}=1.6, J_{3}=7.8 \mathrm{~Hz}\right), 7.27\left(\mathrm{dtd}, 1 \mathrm{H}, J_{1}=0.5, J_{2}=1.7, J_{3}=7.7 \mathrm{~Hz}\right), 7.14-$ $7.19(\mathrm{~m}, 2 \mathrm{H}), 6.91\left(\mathrm{dd}, 1 \mathrm{H}, J_{1}=1.2, J_{2}=7.4, \mathrm{~Hz}\right), 6.88\left(\mathrm{dd}, 1 \mathrm{H}, J_{1}=1.2, J_{2}=7.4, \mathrm{~Hz}\right), 6.83(\mathrm{ddd}$, $\left.1 \mathrm{H}, J_{1}=0.4, J_{2}=1.2, J_{3}=8.2 \mathrm{~Hz}\right), 6.79-6.81(\mathrm{~m}, 1 \mathrm{H}), 6.33(\mathrm{~s}, 1 \mathrm{H}), 2.01(\mathrm{~s}, 3 \mathrm{H}){ }^{13} \mathrm{C}-\mathrm{NMR}: \delta(\mathrm{ppm})$ $151.98,150.23,130.32,130.71,127.26,126.01,123.42,121.62,121.22,119.55,116.76,116.29$, $95.45,90.97,25.05$.

Procedure for the preparation of the dimer 6-methyl-6,12-epoxy-6H,12H-dibenzo[b,f][1,5]dioxocin (5) using microwave irradiation

In a glass tube for microwave reactions equipped with a magnetic stirrer were introduced a suspension of sulphated zirconia $(50 \mathrm{mg})$, o-hydroxybenzaldehyde $(0.0869 \mathrm{~mL}, 0.83 \mathrm{mmol})$, $o$-hydroxyacetophenone $(0.2260 \mathrm{~mL}, 1.66 \mathrm{mmol})$ and acetic anhydride $(0.1181 \mathrm{~mL}, 1.25 \mathrm{mmol})$ in under solvent free conditions at $0{ }^{\circ} \mathrm{C}$ and the mixture was irradiated (initial power of $100 \mathrm{~W}$ ) for $1 \mathrm{~h}$. After the reaction time, the catalyst was recovered by filtration and the filtrate was treated as described in the conventional thermal method described above for dimer 5.

\section{Conclusions}

We have demonstrated the high activity of sulphated zirconia in the solvent-free formation of glycals (1,1-diacetates or acylals), and in the corresponding microwave assisted deprotection reactions. The catalyst can be recycled several times without significant loss of activity, it is highly stable, 
chemoselective, and environmentally friendly, which could open the possibility for an environmentally benign approach for the synthesis of acylals and triacetals under mild reaction conditions.

In case of $o$-hidroxybenzaldehyde, we observed the formation of the corresponding anhydro dimer, as well as the formation of an acetylation product. For $m$-hydroxybenzadehyde and $p$-hydroxybenzaldehyde, aside from the acylation reaction, acetylation also occurs. On the other hand, when we used o-hydroacetophenone with the o-hydroxybenzaldehyde, we observed the formation of the corresponding anhydro dimer methylated on the six position.

\section{Acknowledgements}

The authors would like to thank Consejo Nacional de Ciencia y Tecnología, CONACyT (project 59417) for financial support. L. Nadxieli Palacios is indebted to CONACyT, for the Postgrade Scholarship No. 204780 granted. LLR, EGZ and GNS wish to acknowledge the SNI for the distinction of their membership and the stipend received.

\section{References}

1. Yadav, G.D.; Pujari, A.A. Friedel-Crafts acylation using sulfated zirconia as a catalyst. Green Chem. 1999, 1, 69-74.

2. Ahmed, A.I.; Hakam, E.I.; Samra, S.E.; EL-Khouly, A.A.; Khder, A.S. Structural characterization of sulfated zirconia and their catalytic activity in dehydration of ethanol. Colloids Surf. A Physicochem. Eng. Asp. 2008, 317, 62-70.

3. Das, B.; Krishnaiah, M.; Laxminarayana, K.; Reddy, K.R. A simple and efficient one-pot synthesis of $\beta$-acetamido carbonyl compounds using sulfated zirconia as a heterogeneous recyclable catalyst. J. Mol. Catal. A. Chem. 2007, 270, 284-288.

4. Greene, T.W.; Wuts, P.G.M. Protective Groups in Organic Synthesis, 3rd ed.; Wiley-Interscience: New York, NY, USA, 1999; p. 306.

5. Kocienski, P.J. In Protecting Groups; Georg Thieme Verlag: Stuttgart, Germany; New York, NY, USA, 1994; pp. 156-164.

6. Manjula, K.; Pasha, M.A. Rapid and efficient method for the synthesis of acylals from aldehydes and their deprotection catalyzed by p-toluene sulfonic acid. Synth. Commun. 2007, 37, $1563-1569$.

7. Yin, L.; Zhang, Z.H.; Wang, Y.M. A stable intermediate: a new insight into the mechanism of Lewis acids promoted formation of acylals from aldehydes. Tetrahedron Lett. 2007, 48, 3119-3122.

8. Yadav, J.S.; Reddy, B.V.S.; Sreedhar, P.; Kondaji, G.; Nagaiah, K. Mild and efficient conversion of aldehydes to gem-diacetates using $2^{\text {nd }}$ generation ionic liquids. Catal. Commun. 2008, 9, 590-593.

9. Hajipour, A.R.; Nasreesfahani, Z.; Ruoho, A.E. An efficient and chemoselective synthesis of aldehyde 1,1 diacetate using morpholinum bisulfate as a Brönsted acid ionic liquid under solvent free conditions. Org. Prep. Proc. Int. 2008, 40, 385-391. 
10. Bhattacharya, A.K.; Mujahid, M.; Natu, A.A. An efficient method for the synthesis of acylals from aldehydes under solvent free conditions catalyzed by antimony trichloride. Synth. Commun. 2008, 38, 128-134.

11. Ono, F.; Nishioka, K.; Itami, S.; Takenaka, H.; Sato, T. An improved method for the synthesis of allylic gem diacetates from $\alpha, \beta$ unsatured aldehydes catalyzed by lithium tetrafluoroborate. Chem. Lett. 2008, 37, 1248-1249.

12. Wang, M.; Song, Z.; Gong, H.; Jiang, H. Synthesis of 1,1 diacetates using a new combined catalytic system, copper p- toluensulfonate/HOAc. Synth. Commun. 2008, 38, 961-966.

13. Kumar, S.; Saini, A.; Sandhu, J.S. Gallium (III) chloride: an efficient catalyst for facile preparation of gem diacetates from aldehydes. ARKIVOC 2007, 14, 27-33.

14. Hajipour, A.R.; Khazdooz, L.; Ruoho, A.E. Brönsted acidic ionic liquid as an efficient catalyst for chemoselective synthesis of 1,1 diacetates under solvent free. Catal. Commun. 2007, 9, 89-96.

15. Mirjalili, B.F.; Zolfigol, M.A.; Bamoniri, A.; Amrollahi, M.A.; Sheikhan, N. Chemoselective synthesis of 1,1 diacetates from aldehydes in the presence of $\mathrm{Al}\left(\mathrm{HSO}_{4}\right)_{3}$ under mild solvent free conditions. Russ. J. Org. Chem. 2007, 43, 852-854.

16. Bandgar, B.P.; Joshi, N.S.; Kamble, V.T. A versatile and practical synthesis of 1,1-diacetates fromaldehydes catalyzed by cyanuric chloride. J. Chin. Chem. Soc. 2007, 54, 489-492.

17. Heravi, M.M.; Bakhtiari, K.; Benmorad, T.; Oskoore, $\mathrm{H}_{2} \mathrm{~V}_{5} \mathrm{O}_{4} \cdot 5 \mathrm{H}_{2} \mathrm{O}$ A mild and efficient catalyst for chemoselective conversion of aldehydes to 1, 1 diacetates. J. Chin. Chem. Soc. 2007, 54, $273-275$.

18. Sartori, G.; Ballini, R.; Bigi, F.; Bosica, G.; Maggi, R.; Righi, P. Protection and deprotection of functional groups in organic synthesis by heterogeneous catalysis. Chem. Rev. 2004, 104, 199-250.

19. Desai, U.V.; Thopate, T.S.; Pore, D.M.; Wadgaonkar, P.P. An efficient solvent-free method for the chemoselective synthesis of acylals from aldehydes and their deprotection catalyzed by silica sulfuric acid as a reusable solid acid catalyst. Catal. Commun. 2006, 7, 508-511.

20. Li, T.S.; Zhang, Z.H.; Fu, C.G. Montmorillonite clay catalysis V: An efficient and facile procedure for deprotection of 1,1-diacetates. Tetrahedron Lett. 1997, 38, 3285-3288.

21. Barua, A.; Das, P.J. Solvent free diacetylation of aldehydes using solid acid under microwave irradiation and a simple route to their regeneration. Indian J. Chem. 2008, 47B, 938-941.

22. Hajipour, A.R.; Zarei, A.; Ruoho, A.E. $\mathrm{P}_{2} \mathrm{O}_{5} / \mathrm{Al}_{2} \mathrm{O}_{3}$ as an efficient heterogeneous catalyst for chemoselective synthesis of 1,1-diacetates under solvent free. Tetrahedron Lett. 2007, 48, 2881-2884.

23. Romanelli, G.; Dimitroff, P.; Vázquez, P.; Autino, J.C. Chemoselective preparation of 1,1diacetates of aldehydes, mediated by a Keggin heteropolyacid under solvent free conditions at room temperature. Eur. J. Chem. 2007, 4, 83-89.

24. Kamble, V.T.; Jamode, V.S.; Joshi, N.S.; Biradar, A.V.; Deshmukh, R.Y. An efficient method for synthesis of acylals from aldehydes using silica supported perchloric acid. Tetrahedron Lett. 2006, 47, 5573-5576.

25. Khan, A.T.; Choudhury, L.H.; Ghosh, S. Silica supported perchloric acid: A highly efficient and reusable catalyst for germinal diacylation of aldehydes under solvent free conditions. J. Mol. Catal. A.: Chem. 2006, 255, 230-235. 
26. Jin, T.S.; Zhao, Y.; Gu, S.Q.; Liu, L.B.; Li, T.S. An efficient procedure for the synthesis of 1,1diacetates from aldehydes with acetic anhydride catalyzed by silica sulfate. Ind. J. Chem. Sec. B Org. Chem. 2006, 45B, 1054-1056.

27. Kumar, R.; Tiwari, P.; Maulik, P.R.; Misra, A.K. $\mathrm{HClO}_{4}-\mathrm{SiO}_{2}$ catalyzed chemoselective synthesis of acylals from aldehydes under solvent free conditions. J. Mol .Catal. A. Chem. 2006, 247, $27-30$.

28. Hajipour, A.R.; Zarei, A.; Khazdooz, L.; Mirjaili, B.B.; Sheikhan, N.; Zahmatkesh, S.; Ruoho, A.E. Silica sulfuric acid as an efficient heterogeneous catalyst for the synthesis of acylals from aldehydes under solvent free conditions. Synthesis 2005, 20, 3644-3648.

29. Hydarzadeh, S.; Salavati-Niasari, M. An efficient method for the selective synthesis of germinal diacetates (acylals) from aromatic aldehydes using alumina supported $\mathrm{InCl}_{3}$. J. Mol. Catal. A Chem. 2005, 237, 254-258.

30. Reddy, B.M.; Patil, M.K. Organic Syntheses and Transformations Catalyzed by Sulfated Zirconia. Chem. Rev. 2009, 109, 2185-2208.

31. Xinhua, Q.; Masaru, W.; Taku, M.A. Sulfated zirconia as a solid acid catalyst for the dehydration of fructose to 5-hydroxymethylfurfural. Catal. Commun. 2009, 10, 1771-1775.

32. Murata, M.; Takamiya, N. Method to produce zirconia particles and zirconia transparent dispersion. Jpn. Kokai Tokkyo Koho. 2009, 16.

33. Reddy, B.M. Reddy, G.K.; Rao, K.N.; Katta, L. Influence of alumina and titania on the structure and catalytic properties of sulfated zirconia: Beckmann rearrangement. J. Mol. Catal. A Chem. 2009, 306, 62-68.

34. Negrón, G.; Angeles, D.; Lomas, L.; Martínez, A.; Ramírez, M.; Martínez, R. An efficient synthesis of 6,6 dimethyl-2- (4-nitrophenyl)-1-(R-phenyl)-4,5,6,7-tetrahydro-1H-4-indolones using solid sulphated zirconia catalyst. Heterocycles 2004, 63, 367-372.

35. Negrón, G.E.; Palacios, L.N. Angeles, B.; Lomas, L.; Gaviño, R. A mild efficient method for chemoselective synthesis of acylals from aromatic aldehydes and their deprotections catalyzed by sulfated zirconia. J. Braz. Chem. Soc. 2005, 16, 490-494.

36. Negrón, G.; Angeles, D.; Lomas, L.; Lara, V.H.; Gonzalez, E. Sulfated zirconia-catalyzed synthesis of 3,4-dihydropyrimidin-2(1H)-ones (DHPMs) under solventless conditions. Competitive multicomponent Biginelli vs. Hantzsch reactions. Molecules 2006, 11, 731-738.

37. Negrón, G.; Hernández, C.X.; Angeles, D.; Lomas, L.; Gónzalez, E.; Méndez, J. Comparative study of regioselective synthesis of beta-aminoalcohols under solventless conditions catalyzed by sulfated zirconia and SZ/MCM-41. Molecules 2007, 12, 2515-2532.

38. Negrón, G.; Hernández, C.X.; Angeles, D.; Lomas, L.; Gónzalez, E.; Méndez, J. Microwaveenhanced sulphated zirconia and SZ/MCM-41 catalyzed regioselective synthesis of beta-amino alcohols under solvent-free conditions. Molecules 2008, 13, 977-985.

39. Zane, F.; Melada, S.; Signoretto, M.; Pinna, S. Active and recyclable sulphated zirconia catalysts for the acylation of aromatic compounds. Appl. Catal. A. 2006, 299,137-144.

40. Yang, X.; Jentoft, F.C.; Girgsdies, F.; Ressler, T. Sulfated zirconia with ordered mesopores as an active catalyst for n-butane isomerization. Catal. Lett. 2002, 81, 25-31.

41. Webb, P.A.; Orr, C. Analytical Methods in Fine Particle. Technology Micrometrics Instrument Corporation Norcross: Georgia, USA, 1997; p. 301. 
42. Kulkarni, V.S.; Hosangadi, B.D. A facile synthesis of anhydro dimers of $o$ hydroxybenzaldehydes. Synth. Commun. 1986, 16, 191-193.

43. Ragot, J.P.; Prime, M.E.; Archibald, S.J.; Taylor, R.J.K. A novel route to Preussomerins via 2Arylacetal anions. Org. Lett. 2000, 2, 1613-1616.

44. Adams, R.; Fogler, M.F.; Kreger, W. The structure of disalicyl aldehydes. J. Am. Chem. Soc. 1922, 44, 1126-1133.

45. Jones, P.R.; Gelinas, R.M. The first spectral confirmation for the structures of anhydro dimers of o-hydroxybenzaldehydes. J. Org. Chem. 1981, 46, 194-196.

Sample Availability: Samples of the compounds are available from the authors.

(C)2009 by the authors; licensee Molecular Diversity Preservation International, Basel, Switzerland. This article is an open-access article distributed under the terms and conditions of the Creative Commons Attribution license (http://creativecommons.org/licenses/by/3.0/). 